\title{
En la cresta de la ola. Debates y definiciones en torno a la historia del tiempo presente
}

\author{
Rebeca Monroy Nasr \\ Dirección de Estudios Históricos \\ Instituto Nacional de Antropología e Historia, México \\ remona@mac.com \\ Alberto del Castillo Troncoso \\ (iD) https://orcid.org/oooo-0002-1366-803X \\ Instituto de Investigaciones Dr. José María Luis Mora, México \\ adelcastillo@institutomora.edu.mx
}

Eugenia Allier, César Iván Vilchis y Camilo Vicente (coords.), En la cresta de la ola. Debates y definiciones en torno a la historia del tiempo presente, México, Instituto de Investigaciones Sociales-UNAM/Bonilla Artigas editores, 2020.

La historia del tiempo presente: ¿es una disciplina consolidada o se trata de una moda pasajera? se preguntan los coordinadores de esta obra. Las diecinueve aportaciones originales de investigadores de distintos países recogidas en el libro inclinan la balanza de manera categórica hacia la primera propuesta. Y lo hacen en torno a dos tareas fundamentales: por un lado, discutir y poner sobre la mesa los temas y problemas teórico-metodológicos más relevantes de este tipo de historia, y por el otro, acercar al público mexicano a una manera de discutir los problemas históricos que ha tenido mayor arraigo en algunos países de Europa y el Cono Sur y que en nuestro país apenas empieza a despuntar.

Cuando hablamos de Historia Reciente no hablamos de un campo homogéneo, sino de un espacio en construcción. Algunas de las cuestiones que se discuten en este importante texto son la selección del concepto más adecuado para referirse a estos estudios, que se remiten a la "Historia reciente" en el caso del Cono Sur, a la "Historia inmediata", vinculada a Francia y a la "Historia del tiempo (c) (†) (8) 4.0 Internacional 
presente", de mayor arraigo en España, Colombia y México. Por supuesto, también están a discusión las implicaciones teóricas del llamado "presente histórico", así como las implicaciones éticas, políticas y epistemológicas del historiador y sus retos ante el manejo de las distintas fuentes documentales, orales y visuales.

La primera sección: "Debates y definiciones. Temporalidad, temáticas y aspectos sociopolíticos" plantea un recuento en torno a los debates sobre la definición de este campo historiográfico.

La segunda sección: "Fuentes y metodologías" expone las distintas formas de acercamientos vinculados a nuestra historia reciente, los cuales están mediados por las premisas hermenéuticas utilizadas, pero también por el tipo de documentos consultados y sus múltiples lecturas y acercamientos. Se trata de un sugerente repaso que subraya el papel histórico del tratamiento de las víctimas y sus múltiples posibilidades analíticas.

El tercer y último bloque analítico de este libro lleva por título: "Construcción de los campos, temáticas y balances historiográficos" y propone distintas rutas de discusión en torno a estos importantes temas y problemas en los casos de México, Argentina y Brasil.

La primera parte inicia con el texto "Historia y tiempo presente. La zona de la experiencia desnuda”, de Ilán Semo, investigador de la Universidad Iberoamericana, que nos deja ver como en un laberinto con el Minotauro, la necesidad de la historia del tiempo presente de trabajar en diferentes ámbitos desde el filosófico, el psicoanalítico, el analítico y el conceptual (historia intelectual), para poder armar una historia del tiempo presente con base en los elementos políticos y culturales, y para ello se propone encontrar la claridad que merecen los estudios en dónde intervienen una diversidad de factores que es necesario contemplar, como el concepto de memoria -las batallas de la memoria- con el habla como eje central en la historia oral, el recuerdo del recuerdo y la transformación de la memoria en un dispositivo de la historia. Se trata pues del manejo del tiempo en una cronotopía general, de un pasado que no pasa, que está presente en la historia contemporánea, en donde la línea del pasado y el presente es movediza. Una frase cierra con claridad 
la propuesta del autor, "Lo global es buscado cada vez más en la singularidad de lo local”.

El ensayo de Eugenia Allier, investigadora del Instituto de Investigaciones Sociales de la UNAM, se titula "El tiempo presente en la historia: generaciones, memoria y controversia", viene a destacar muchos de los hilos de Ariadna, en ese laberinto, para poder comprender el trabajo del presente en la historia. Su narrativa recorre posturas diferentes, desde el Institute d'Histoire Moderne e Contemporaine, en Francia, y la distancia que tomó con respecto al análisis de aquella historia que sugería la necesidad de la distancia y el tiempo para su análisis.

En este capítulo, la autora nos dota de los elementos necesarios para comprender las contribuciones de sociólogos, historiadores y filósofos para aclarar y profundizar en las definiciones de este tiempo presente como periodo histórico y no solo como una forma de historiar. Así, la historia del tiempo presente tiene sus propios ritmos, litorales y formas de aproximación que bordan en la historia de la memoria, que converge en el concepto de la coetaneidad, que es parte sustancial al contener de tres a cuatro generaciones que comparten un presente histórico y una experiencia en común. Coincidimos con ella en el sentido de incorporar otras fuentes actuales que hay que considerar, como los videojuegos, la TV, los blogs, las páginas de internet y, cada vez más, los memes, el Instagram, el Facebook y, sobre todo, la fotografía, que en los otros ensayos no encontramos como fuente documental y que en estos tiempos sería necesario incluirla. Así como en la memoria, el testimonio y el testigo son fundamentales, la fotografía y el fotógrafo también dotan de presencia, de instantaneidad, son percutores de la memoria y representan una huella de los eventos.

Guadalupe Valencia, del Centro de Investigaciones Interdisciplinarias en Ciencias y Humanidades trabaja en su texto "El tiempo social: una visión transdisciplinaria" el enfoque de la multi, pluri, inter y la transdisciplina, que son elementos que pueden intervenir en el análisis del tiempo presente, en donde se analizan y categorizan sus posibilidades, sugiriendo el trabajo transdisciplinario para abordar el tema del tiempo como dimensión fundamental. En este sentido, aborda el concepto de tiempo desde la sociología, diferenciándola de otras 
disciplinas, al hablar de diversas temporalidades y de los procesos temporales, pues, señala: "las cosas no transcurren en el tiempo sino temporalmente". En este caso la autora nos sumerge en los conceptos de tiempo, al señalar que no existe uno ni muchos tiempos, sino contemporalidades que se expresan en sincronía de transcursos. Con ejemplos claros, metáforas fecundas, novelas donde aparece el uso del tarot y otros ejemplos, la autora nos lleva a entender que hay una red de temporalidades, una malla tupida de "ahoras", que convocan a pasados y prefiguran futuros, elementos que deben ser considerados al momento de hacer historia del tiempo presente, de los testimonios orales, relatos de momentos semejantes entreverados con sus diferencias, de memorias sesgadas por lo vivido.

Rogelio Ruiz Ríos, del Instituto de Investigaciones Históricas de la Universidad Autónoma de Baja California aborda en su texto "Dos temas paralelos al auge de la historia del tiempo presente: el tiempo histórico y las relaciones entre historia y memoria" el tiempo histórico y las relaciones entre historia y memoria, elementos sustanciales de la forma de trabajo del historiador del tiempo presente. Alude a que la transición entre los siglos XX al XXI ha traído la necesidad de dilucidar sobre el tiempo, las temporalidades y, sobre todo, el tiempo histórico. Para ello, abordará el presentismo, ya que se ha visto en la necesidad de acuñar nuevas definiciones conceptuales al verse inmersas en las temporalidades del pasado y futuro. Con ello son cuestionables los lineamientos y la epistemología de los historiadores del pasado, necesitando plantearse nuevas maneras de historiar, en donde el tiempo es un elemento por trabajar, repensar, analizar y replantearse, algo que se modificó después del posmodernismo y que requiere determinar las nociones del tiempo histórico.

Cecilia Macón, investigadora de la Universidad de Buenos Aires, nos lleva a uno de los temas más relevantes de este tipo de historia en su texto, "Emociones e historia reciente: hacia una refiguración de la distancia histórica”. De esta manera, la autora se refiere a momentos icónicos en Argentina, como es la marcha del 10 de mayo de 2017, donde medio millón de personas protestaron con los pañuelos blancos de referencia directa a las Madres de la Plaza de Mayo. Y es justamente aquí el ejemplo claro de lo que se ha escrito en los capítulos anteriores sobre las 
generaciones sobrevivientes, las coetáneas, las que heredaron, las que estuvieron presentes. Aquí el ejemplo es clarificador al enunciar las emociones que se tiene de indignación, ironía, inquietud, esperanza, ira, alegría, entremezcladas. La puesta en página nos refiere justo a esa cercanía del presente, que es pasado inmediato. $Y$ en ello dedicará sus líneas a aclarar qué es la historia del tiempo presente, qué son las emociones y cómo problematizar la relación de la historia y los afectos. En este sentido nos recuerda los trabajos realizados desde la historia cultural y del arte de la mirada de la investigadora británica Andrea Noble, que analizó con su mirada penetrante el caso de la historia de la fotografía en México en el siglo pasado.

Fédérique Langue, investigadora de Le Centre National de la Recherche Scientifique, en París, nos presenta el ensayo "Memoria y emociones de un tiempo presente latinoamericano", en el cual refuerza los planteamientos que se han venido manifestando, pero en esta ocasión subraya el papel que le corresponde al historiador del tiempo presente como científico social y ciudadano. También destaca cómo el pasado siniestro de algunos países latinoamericanos vivió las dictaduras con una comunidad de significados compartidos. Así, Chile, Argentina, Uruguay, Brasil, entre otros, han avanzado en estudios del tiempo presente, lo que ha implicado un reto epistemológico para los estudiosos del tema. Entre los trabajos de los latinoamericanistas, la autora va a encontrar una diversidad de metodologías y acercamientos críticos a la información y las modificaciones y propuestas de análisis de cada región, pero que convergen en ejes similares, por lo que asienta que: "Los regímenes emocionales contribuyen en este aspecto a explicitar los regímenes de historicidad y los retos políticos y sociales que conllevan".

Gabriela Rodríguez Rial, investigadora de la Universidad de Buenos Aires, y su texto, "Historia conceptual e historia del presente: ¿por qué los conceptos importan cuando se narra historia coetánea?” nos presenta de qué manera se puede conceptualizar la historia del presente y penetrar en el mundo de la sociohistoria, rompiendo márgenes historiográficos y metodologías de abordaje. En su texto, la autora se siente más inclinada a llamarla, reciente historia coetánea, porque ello implica la coetaneidad de diferentes temporalidades en un mismo tiempo, dentro del terreno de lo subjetivo y la experiencia. De nuevo el tiempo es parte sustancial de los 
conceptos de la historia presente. En su quehacer como politóloga, Rodríguez Rial ha encontrado en la historia conceptual la estructura que le da paso a trabajar su interés teórico con la política contemporánea. Para ello, revisa los conceptos, definiciones, problemas y hallazgos de la historia conceptual, pues plantea que ésta tiene parecidos con la sociología de los conceptos políticos y jurídicos, en lo que ella es especialista.

En el último ensayo de la primera parte, titulado "Ética y política en el historiador del tiempo presente", Eugenia Allier propone analizar el papel histórico del historiador del tiempo presente, por el nivel que tiene de involucramiento en esa memoria social, y por ello veremos la importancia que reviste este tema, porque finalmente hay una intención clara del historiador cuando se busca tener un criterio de justicia y equidad, de búsqueda de la verdad con el compromiso adquirido. Para Allier, muchas veces la distancia que se puede tener con el acontecimiento es parte sustancial por evaluar, pero sobre todo analizará el caso de aquellos historiadores que participan en los tribunales de justicia como testigos expertos, y el papel que deben fungir en la "búsqueda de la verdad" la cual es normativa, definitiva y apremiante. El historiador del tiempo presente y la intervención en la comunidad, son analizados con ejemplos claros y notables de la historia que develan una serie de secretos. En particular, nos atrajo el tema de "El cuidado de sí y de los otros...", en cuanto a la responsabilidad que tiene el historiador "con la verdad histórica, pero también con el colectivo social, asumiendo las dimensiones ética y política de su labor". En este sentido, concluye la autora, las respuestas del tiempo presente están en el pasado inmediato, hay que aclararlas, evitar el olvido, recuperar la memoria, que es identidad, justicia, memoria para localizar la verdad histórica como un compromiso ético y social.

La segunda parte del libro inicia con el ensayo titulado, "Historia reciente de América Latina como outsider: investigar el pasado cercano de una tierra extranjera". En el artículo, Benedetta Calandra, investigadora de la Universidad de Bérgamo, expone distintos problemas relacionados con la historia presente a partir de su propia condición de investigadora outsider, una académica italiana especializada en los estudios latinoamericanos, preguntándose para ello por la 
cuestión del espacio, entendido éste no solo en su dimensión geográfica, sino en un sentido más amplio de pertenencia, lo que la lleva a dedicarse a la investigación de los derechos humanos estando en Inglaterra en el año de 1999, unos pocos meses del estallamiento del caso Pinochet, toda vez que como señala la propia autora, los investigadores tienden a moverse en un panorama transnacional con contextos de origen, formación y temas que incluyen a Europa, los Estados Unidos y América Latina.

Por su parte, Fernando González, investigador del Instituto de Investigaciones Sociales de la UNAM, en su artículo titulado "Maneras de testimoniar en situaciones de abuso sexual”, analiza una serie de relatos de víctimas de violación y abuso sexual en distintos contextos en los que se retoma el llamado "tiempo del testigo" evocado por Annette Wieviorka y que alude al juicio de Eichmann en 1961, que marcó un antes y un después en este tipo horizontes interpretativos basados en el tiempo de espera de las víctimas y su derecho a procesar de distintas maneras este tipo de violencias. El autor recupera aquí la subjetividad de los sujetos y las diversas maneras en que los testimonios orales pueden ser leídos e interpretados, atendiendo a sus espacios públicos y privados, a sus condiciones de anonimatos y celebridades.

En el texto "Las víctimas en la historia del presente: un peligroso (en)canto de sirenas", Juan Sebastián Granada-Cardona, Doctor en Ciencias Políticas de la UNAM, se pregunta por el proceso histórico que ha llevado a las figuras de la víctima y el victimario al lugar preponderante que ocupan en las investigaciones del tiempo presente, a partir de las nuevas lecturas propuestas desde la psiquiatría y el derecho y confirmadas por procesos históricos como el de la Shoa, convertido en el paradigma de los modelos de la construcción de la memoria, hasta desembocar en casos como el colombiano, en el que el relato de víctimas y victimarios ocupa un lugar central no solo en la reflexión académica sino sobre todo en el espacio público de la discusión política. Frente a esta realidad, el autor recomienda el diálogo de la historia con otras disciplinas como la antropología, la sociología y la psicología y, sobre todo, flexibilidad y agudeza para el reconocimiento de una diversidad de miradas desplazadas o marginadas a lo largo de este tipo de procesos. 
Por su parte, Alicia de los Ríos, investigadora de la Universidad de Chihuahua, abre un debate fundamental en torno a la necesidad de recuperar los testimonios de la violencia en su artículo "Entrevistar perpetradores de violencia en el siglo XXI. Problemas e intersecciones entre la historia oral e historia del presente". Escrito en primera persona, desde su lugar como hija de desaparecidos, abogada militante en el campo de los derechos humanos e historiadora, la autora va señalando las coordenadas para ir construyendo una metodología de la contrainsurgencia y una "etnografía en las sombras" que permita acceder a una pieza clave para la comprensión de este tipo de procesos, el testimonio de los perpetradores, no desde el vínculo de la empatía, sino con la distancia crítica que permita su análisis desde el horizonte de la búsqueda de una posible objetividad, ya que, como señala Alicia: "los perpetradores fueron espectros que se diluyeron junto a las propias personas militantes desaparecidas".

En esta búsqueda de estos espectros también desaparecidos, la autora reconstruye el valioso testimonio de su entrevista con un ex agente de la Dirección Federal de Seguridad que participó en la contrainsurgencia durante aquellos años y que después fue desplazado por la propia burocracia de las instituciones oficiales que lo relegaron a un segundo término. Con ello, abre un importante espacio para intentar descifrar la lógica de la opresión que operó detrás de la mecánica contrainsurgente del Estado, lo cual representa un vacío casi total para este tipo de trabajos en la actualidad.

Por su parte, Camilo Vicente Ovalle, investigador de la UNAM, complementa el texto anterior y nos permite acercarnos en su artículo, "Archivo y las huellas del presente" a algunos elementos centrales para la reflexión sobre la relación y las tensiones entre el archivo y la historia del tiempo presente.

La alternancia democrática del 2000 abrió en México la posibilidad de un acceso a la documentación del régimen autoritario que se concretó en el traslado de los archivos de la represión al Archivo General de la Nación. Sin embargo, este acceso fue muy limitado desde el principio. Primero, a través del traslado con los documentos de un agente de la represión como controlador y censor de la documentación en el AGN y posteriormente con La Ley Federal de Archivos que 
introdujo el término de la confidencialidad para acotar el acceso a la documentación y reducir un debate político a cuestiones supuestamente técnicas.

Una de las aportaciones centrales de este artículo consiste en argumentar de qué manera estos archivos de la represión forman parte de la estructura de poder que les dio sentido y hay que leerlos desde ese lugar de enunciación. En este sentido, esa documentación resulta clave para repensar las permanencias y continuidades del antiguo régimen con la incipiente y vulnerable democracia mexicana, que todavía no termina de cuajar y corre el riesgo de quedar sepultada debajo de los intereses de las elites políticas y económicas que sostuvieron al régimen anterior y permanecen en su sitio privilegiado en los gobiernos democráticos posteriores.

Una sugerente reflexión de César Iván Vilchis, investigador de la UNAM, nos acerca a la necesidad de trabajar con la documentación más reciente en su texto titulado "Televisión e internet: fuentes para una historia del tiempo presente". En el caso de la primera, alguna vez descrita por Carlos Monsiváis como "La caja idiota", han predominado una serie de prejuicios que han impedido repensarla de manera crítica como una valiosa fuente que requiere de una hermenéutica especializada, que permita entenderla como una construcción social y cultural, la cual no solo brinda contextos e informaciones importantes en torno a los hechos, sino que ha contribuido como ningún otro vehículo a moldear la mentalidad de amplios sectores de la población.

Por lo que respecta al internet, se subrayan las distintas maneras en que las nuevas plataformas digitales han transformado el tradicional oficio solitario del historiador a través del correo electrónico, las videollamadas, los WhatsApp y los chats, pasando por los sitios web, el Facebook, el Instagram y el YouTube, todos los cuales configuran como nunca la comunidad virtual que envuelve y le da nuevos sentidos a la investigación. Los cambios han sido vertiginosos y el retraso teórico y metodológico respecto de los nuevos avances resulta evidente. Aportaciones como las de este artículo nos permite vislumbrar algunas de estas tensiones y fracturas y nos invitan a construir puentes para poder ir clarificando las rutas a seguir en los próximos años. 
En "El Sol de Sinaloa: una fuente para reconstruir la historia del tiempo presente sobre la violencia política en México a finales del siglo XX”, Sergio Arturo Sánchez Parra cierra este segundo bloque y nos acerca a un caso concreto leído desde la perspectiva de la historia regional: la violencia política asociada a organizaciones guerrilleras en los años setenta del siglo XX a través de la lente particular de un periódico local, pero vinculado a una cadena periodística nacional perteneciente a García Valseca, un exmilitar anticomunista convertido en empresario de la prensa. $\mathrm{El}$ artículo hace explicita la metodología con la que se trabaja en esta investigación, en el marco de la historia del tiempo presente y con referencia a distintos autores como Roger Chartier y Michel de Certau, que se han convertido en referentes hermenéuticos de este tipo de trabajos y su interrogación de las fuentes documentales, todo lo cual lleva al autor a considerar a $\mathrm{El} \mathrm{Sol} \mathrm{como} \mathrm{uno} \mathrm{de} \mathrm{los} \mathrm{actores}$ políticos que busca posicionar en el espacio público una cierta visión de las cosas construida a partir de un determinado lugar de enunciación político y social.

El artículo "La historia vivida y el estudio de la violencia en México: conflictos historiográficos y dilemas metodológicos", de Rodolfo Garmiño, investigador de la Universidad Iberoamericana inicia el tercer y último apartado del libro. El autor plantea la existencia de un vacío y una ausencia de un modelo histórico para el análisis de la violencia política del presente debido a lo que él denomina una "excesiva colonización" del proyecto intelectual de la Escuela de Annales que habría convertido a la historia en un discurso de Estado.

En el caso mexicano, la alternancia democrática del año 2000 puso las bases para replantear el modelo tradicional del quehacer histórico, repensar un giro historiográfico y abrir el espacio para una historia del tiempo presente, con todos los retos conceptuales y metodológicos que ello implica, lo que puso en la agenda el debate en torno a la cuestión de los derechos humanos. La violencia, sin embargo, ha continuado y con ella, los casos paradigmáticos con la intervención del Estado. El caso de Ayotzinapa en el 2014 es solo uno de los más representativos de una larga lista.

La violencia, como subraya el autor, no es un asunto del pasado, sino que se ejerce en un tiempo circular que incluye el presente. A pesar de ello, todavía no se le 
historiza con un marco amplio que permita profundizar en ella, lo que obliga a escribir una nueva historiografía con un enfoque interdisciplinario tanto en las investigaciones como en el archivo, con una crítica hermenéutica de las fuentes orales y un nuevo ejercicio de la escritura. Vinculando esta argumentación con el giro lingüístico, el autor propone una nueva escritura de la historia, con un lugar de enunciación diferenciado, que piense y problematice las cosas desde las múltiples memorias de experiencia vivida, de lo contemporáneo.

En "Consideraciones sobre política e historiografía: el campo de la Historia Reciente en la Argentina”, Marina Franco problematiza la diversidad que ha experimentado el estudio de la historia reciente para este país del extremo sur del continente. Partiendo de la base de que la más reciente dictadura militar concebida como terrorismo de Estado constituye la matriz de apoyo del surgimiento de un estudio sistemático del tiempo presente y después de una primera etapa postdictatorial adversa en el campo de la memoria se produjo una renovación en el campo de este tipo de estudios, lo que permitió repensar algunos temas y abrir otras perspectivas, como la complicidad de la dictadura con algunos sectores sociales y la experiencia de la militancia revolucionaria en los setentas.

Tal como lo señala la autora, fueron los últimos 15 años de este nuevo siglo, con la inauguración de un nuevo ciclo político a cargo de Néstor y Cristina Kirchner los que permitieron un desarrollo exponencial de estos temas aparejado con un notable incremento en los presupuestos académicos y universitarios, lo que ha permitido el surgimiento de diversos anclajes territoriales y la puesta en escena de una gama de intereses temáticos que incluyen la represión, el género, la militancia política, los exilios, las juventudes, el consumo cultural, las relaciones familiares, la moda, la educación y los avatares de la vida cotidiana, entre otros tópicos que han ensanchado estas mirada históricas que se nutren de la experiencia vivida y de lo coetáneo.

La situación actual es bastante compleja, el regreso de sectores de derecha con el gobierno de Macri introdujo nuevas tensiones en los relatos sobre el pasado, con la impugnación correspondiente respecto de las políticas de derechos humanos de los años anteriores. En tal contexto, para la autora la historia reciente en Argentina 
enfrenta nuevos desafíos que ya no miran hacia afuera y la búsqueda de la legitimidad, sino hacia dentro, con respecto a sus propias fronteras epistemológicas.

Silvia Jensen y Soledad Lastra plantean una serie de "Reflexiones sobre el campo de estudio de los exilios en Argentina (1996-2016)", en la que continúan la discusión anterior centrándose en la problemática de los exilios a partir del vigésimo aniversario del golpe militar.

A lo largo del texto se indaga de qué manera la temática del exilio se posicionó en el espacio público como una de las modalidades de interpretación del pasado, se exploran las batallas por el sentido del mismo, mediando entre la explosión de la militancia en los setenta y la sanción de una memoria oficial sobre el terrorismo de Estado, se buscan los orígenes del campo de estudios sobre el exilio político hasta su institucionalización en el país en los primeros años del nuevo siglo y se vinculan los cambios en la agenda de los temas con las transformaciones de lugar social de las prácticas historiográficas, tales como las nuevas investigaciones que profundizan en las marcas del exilio en la memoria; el avance de la reconstrucción histórica de las dinámicas del exilio por capítulos nacionales; la multiplicación de los trabajos que piensan las relaciones entre el exilio y el transnacionalismo político; la indagación sobre los recorridos de las formaciones políticas en el destierro y la multiplicación de los exilios sectoriales que avanzan en temas como la ocupación profesional, la orientación sexual, el género, entre otras muchas posibilidades.

Finalmente, Rodrigo Patto Sá Motta aborda "El campo de investigaciones sobre la Historia Reciente en Brasil, de su formación al estado actual”, para lo cual discute sobre las relaciones entre la historiografía y las otras áreas que han producido valiosos conocimientos sobre la historia reciente en aquel país.

El caso de Brasil es muy peculiar. Los estudios de historia reciente se remiten al espacio de la dictadura militar de la década de los sesenta. Un régimen que reprimió a la oposición generó una gran cantidad de documentación y creó un gran impulso para la investigación académica.

La transición democrática de los ochenta se pactó sobre un manto de impunidad en torno a los crímenes de la dictadura. En términos generales, como señala el autor, la dictadura militar fue parcialmente derrotada, pero no superada. 
De esta manera la Constitución de 1988 representa al mismo tiempo un hito en la conquista de los derechos civiles y políticos, y el perdón a las violaciones a los derechos humanos de los años anteriores.

Pese a todo, en los gobiernos de Lula y, sobre todo, de Dilma Rousseff se registraron avances importantes en el acceso a la información con el establecimiento de la Comisión Nacional de la Verdad en el año 2012, lo que les dio continuidad a importantes hechos anteriores, como la voluntad política de trasladar la documentación de los servicios de inteligencia del régimen militar al Archivo Nacional seis años antes.

Si bien en aquellos años hubo un impulso a la investigación como nunca, la crisis posterior del gobierno de Dilma y el regreso de la derecha plantean un horizonte de mayor impunidad, con espacios cada vez menores para el ejercicio democrático, una reducción de la inversión pública en la investigación y el fortalecimiento de los mecanismos de censura.

La sólida producción académica brasilera de los últimos años en torno a temas relacionados con la historia reciente tiene un carácter transdisciplinario y pasa por la incorporación de nuevas generaciones de historiadores a este campo, trazando una diversificación de temas que han agregado a la historia política los enfoques provenientes de la historia cultural.

Como señala el autor, la continuidad actual de este tipo de estudios dependerá de la capacidad de resistencia por parte de las instituciones democráticas construidas desde el fin de la dictadura ante los embates de un gobierno cada vez más autoritario.

En síntesis, esta importante obra colectiva nos permite un acercamiento entre las distintas historiografías al tiempo que nos transmite con elocuencia la imposibilidad de vivir este tipo de historia desde acercamientos únicos o excluyentes. Por el contrario, lo que salta a la vista es un mapa complejo con el trazo de distintos caminos y rutas que se entrecruzan de manera constante. Un llamado a la diversidad. Estamos frente a un trabajo que se convertirá en los próximos años en una fuente de consulta indispensable para acercarse al complejo mapa de una historia en 


\section{Rebeca Monroy Nasr / Alberto del Castillo Troncoso}

construcción, que admite distintos puntos de partida y que discute con distintas premisas conceptuales. 